\title{
Evidence for several components of word familiarity
}

\author{
FRANÇOISE CORDIER \\ Université de Poitiers, Poitiers, France \\ and \\ JEAN-FRANÇOIS LE NY \\ Université de Paris-Sud, Centre Scientifique d'Orsay, Paris, France
}

\begin{abstract}
Familiarity with a word can be divided into two main components: familiarity with the form of the word (due to both its lexicality and its specific form) and familiarity with its meaning. In this study, ratings of familiarity were compared for words whose meaning was unknown to participants (UM words), for words of known meaning (KM words), and for unknown words (U words). Linguistic and experiential frequencies were equivalent. Rated familiarity was lower for UM than KM words and even lower for U words. Next, we built pseudowords from these stimuli by changing one letter and submitted them to two familiarity rating tasks that differed in the nature of the additional stimuli: either only nonwords or nonwords plus words. It was assumed that familiarity ratings would be lower for pseudowords built from UM words than for pseudowords built from KM words. The data were consistent with this assumption, and ratings depended on the initial categories of stimuli. These results support the view that usual word familiarity has two components, familiarity with form and familiarity with meaning, and a double source, processing of word form and processing of word meaning. The full set of these materials and norms may be downloaded from www.psychonomic.org/archive.
\end{abstract}

Tasks designed to study word recognition and lexical access and, in particular, to study lexical decision tasks and word pronunciation tasks, often use word familiarity values. A theoretical notion of familiarity appears in several models of recognition in memory (Gillund \& Shiffrin, 1984; Goldinger, 1998; Hintzman, 1984; Murdock, 1982; Ratcliff \& McKoon, 1988). It has been assumed by several authors (Amano, Kondo, \& Kakehi, 1995; Balota \& Chumbley, 1984; Balota, Pilotti, \& Cortese, 2001; Joordens \& Becker, 1997) to play a major role in lexical decision making. Familiarity is viewed in these models as a property of the representations stored in memory, in particular words, or as a state in processing, and assumed to be the output of an interaction between information from the input stimuli and these representations. However, familiarity is commonly viewed in these studies as a unitary property or state.

However, it is generally admitted that word representation in memory has two main constituents: the representation of the word form, which is orthographic in the case of written words, and the meaning of the word. There is now fairly general agreement that these two types of lexi-

Correspondence concerning this article may be addressed to F. Cordier, Laboratoire de Psychologie, Université de Poitiers, LaCo-M.S.H.S., 99, avenue de RecteurPineau, BP 632, Poitiers, France 86022 (e-mail: francoise .cordier@mshs.univ-poitiers.fr).

$$
\text { Note-This article was accepted by the previous editor, }
$$
Jonathan Vaughan. cal knowledge, whatever their nature, contribute to lexical decision and word recognition. Many other properties of the word representation, including frequency of use, pronounceability, letter or syllable structure, spelling-sound consistency, orthographic similarity with neighborhood, and so on, play a role in visual word recognition. However, much evidence also supports the contribution of meaning to word processing (Balota \& Chumbley, 1984; Borowsky \& Masson, 1996; Hino, Lupker, \& Pexman, 2002; Kawamoto, Farrar, \& Kello, 1994; Masson \& Borowsky, 1995; Morton, 1969, 1970; Murrell \& Morton, 1974; Pecher, 2001; Schuberth \& Eimas, 1977; Stone \& Van Orden, 1993; Van Orden, Bosman, Goldinger, \& Farrar, 1997; Van Orden \& Goldinger, 1994).

The role of word familiarity in word processing has been presented by several authors (Azuma \& Van Orden, 1997; Balota \& Chumbley, 1984; Balota \& Spieler, 1999; Durkin \& Manning, 1989; Gernsbacher, 1984) as being complementary to that of meaning. Balota and Chumbley (1984) viewed these two components as forming composite information, and Balota and Spieler (1999) wrote that a lexical decision is possible "because words are more familiar than nonwords (also more meaningful)."

Meaning as knowledge can be assumed to involve familiarity as a result of speakers' experience with the words through their semantic processing. Gernsbacher (1984) pointed out that word experience must be considered across all modalities concerning the word. Familiarity with a word, however, is also presumably acquired by a speaker, not only from encountering and perceiving it, but 
also from the semantic operations involved in its processing. This is particularly true of comprehension, which requires the activation of both the word form representation and its meaning. Familiarity with these two representations may then be simultaneously increased every time the word is processed.

If this assumption proves to be true, familiarity values usually considered for words do not express a single global state of familiarity associated with these words, but rather a summation of at least two distinct familiarity values, each associated with one of the two main parts of the word representation - form and meaning.

The studies showing that the addition of meaning to previously nonmeaningful strings influences word recognition (Forster, 1985; Whittlesea \& Cantwell, 1987) are partially relevant to this point. Whittlesea and Cantwell assigned a definition to pronounceable nonwords and found that their participants later produced considerably more letters for these stimuli in a letter-detection task than for nonwords that received only visual processing in the absence of meaning. Forster conducted a study that used obsolete words, unknown to the participants, that initially produced no masked-repetition priming of lexical decision time. When these words were made known to the participants and given a meaning, they did produce this effect. Forster, however, made no clear distinction between knowledge of the word and knowledge of its meaning.

Le Ny (1989) suggested another type of study, one based on the observation that memory contains a type of word never used in experimental studies: namely, words that are known, but that have no meaning for us. In our long-term memory, we all have intuitive knowledge of word forms that we know to be actual words in our language, although we are unable to say what they mean. Although these unknown meaning (UM) words are a marginal part of everyone's lexicon, they permit the natural dissociation of familiarity with the word form representation from familiarity with word meaning, which is normally associated in regular, known meaning (KM) words. This UM versus KM factor can be used in experiments to help us to better distinguish the respective roles of the constituents of lexical units in rating familiarity with KM words and in processing them.

On the other hand, the use of various kinds of nonwords in lexical decision tasks has shown that the form of these nonwords - in particular, their lexicality in terms of their conformity with the regularities of the language in question - results in differences in judging familiarity. This suggests that familiarity with a word form can also differ according to two subcomponents involving (1) the representation of the specific word form, which depends on the particular word, and (2) a general word form, which depends on the language, in this case, French. If there are indeed these various components of familiarity - that is, the form of the word (general and specific) and its meaning - then UM and KM words, unknown words ( $\mathrm{U}$ words), and nonwords should differ on these dimensions, and this should produce different modes of processing and rating. Ratings of familiarity for such categories of words or nonwords may make it possible to dissociate these assumed components.

The main goal of this article is to provide data on how knowledge of word meaning and orthographic lexicality (in French), plus specific word form, contribute to word familiarity ratings when other word properties are controlled for. UM, KM, and U words were first selected and rated for familiarity in contrast to several categories of nonwords. Because pseudowords can be assumed to conserve some, but not all, of these components of familiarity, pseudowords were then constructed from the original words and rated.

The results are discussed in relation to the role of the components of familiarity in word processing. We consider this to be a useful approach for the further study of lexical decision and word recognition, in light of their respective contributions to these tasks.

\section{Selection and Verification Ratings of the Experimental Stimuli}

Selection. The main stimuli used in the experiments were first selected and checked in a series of preliminary rating sessions. The experimenters produced a pool of 143 words intuitively assumed to correspond to the experimental requirements and, in particular, to comprise many words that would have a meaning unknown to undergraduates. All the stimuli in this pool were bisyllabic or trisyllabic words, and their frequencies were less than 6.55 per million, according to the Lexique database (http://www .lexique.org; New, Pallier, Ferrand, \& Matos, 2001).

The words were submitted to 72 undergraduate students of psychology from the University of Reims, France, all of whom were native French speakers. They took part in this experiment as part of their classroom work. They were divided at random into three groups of 24 participants each. The words were assigned to three lists of approximately equal length and typed on separate sheets of paper. The words were typed on each successive line of the sheet, with three empty columns to the right, headed C1, C2, and $\mathrm{C} 3$. These interpretations of the headings were given to the participants in the spoken instructions and were also written at the top of the sheet:

C1: I am sure that this word is a French word, and I know what it means.

C2: I am sure that this word is a French word, but I don't know what it means.

C3: I don't know whether this word is a French word or not.

The participants were made aware of the existence in their language and memory of the three kinds of words defined above and instructed to examine each of the words 
on the sheet, to assign it to a category, and to indicate their choice by putting a cross in the appropriate column. They were also required to write a brief definition of the word whenever they chose category $\mathrm{C} 1$.

These data, and the matching method defined below, were used by the experimenters to choose 15 stimuli for each of the three main experimental categories, which were as homogeneous as possible.

The first contained KM words, all of which had been marked in the $\mathrm{C} 1$ column and their meaning defined in an approximately correct way. Ampère (ampere) and scoliose (scoliosis) are examples of this category. The third category contained U words, of which $95 \%$ were marked in column $\mathrm{C} 3$ by all the participants, and the other $5 \%$ by all participants but one of the participants in $\mathrm{C} 2$ or C1. Cattleya (cattleya) and pataras (protective shroud) are examples of this category. The participants could view these words as regular, pronounceable nonwords.

There were minor between-participants variations for UM words, which made up the second category. Overall, $73 \%$ of the UM words were marked in the $\mathrm{C} 2$ column by all participants; $22 \%$ were marked in $\mathrm{C} 2$ by all but a few participants (who marked them in $\mathrm{C} 3$ instead); and 5\% were marked by all but a few participants in C1. Only a third of the latter words were defined approximately correctly. Abscission (abscission), bernacle (barnacle goose), and dolence (dolefulness) are examples of words in this category.

Additional verification. All the words were also matched with a derived list, BRULEX, constructed by Content, Mousty, and Radeau (1990) for experimental use. This involved the following criteria:

Grammatical category. All the words were nouns;

Linguistic frequency. Linguistic frequencies were categorized according to the BRULEX norms, similar to Lexique norms;

Suffixed words. None were used because access via the word root is efficient for processing new words;

First letter frequency. French first letter frequency was matched on the basis of the BRULEX data because the first letters of written words are important for their recognition (Andrews, 1997; Cole, Beauvillain, Pavard, \& Segui, 1986; Content \& Radeau, 1988; Lima \& Inhoff, 1985);

Orthographic neighbors. The selected words had no recognizable orthographic neighbors; neighborhood seems to have a different effect for different languages. French words are less rapidly recognized when they have more frequent orthographic neighbors (Grainger, 1990; Grainger, O'Regan, Jacobs, \& Segui, 1989, 1992; Grainger \& Segui, 1990; Segui \& Grainger, 1990), whereas English words are more rapidly recognized (see Andrews, 1997, for a review);

Uniqueness point. The stimuli were matched for this point, situated after the first syllable. Radeau (1991) has shown the effect of its location in the visual modality.

Some other properties, treated as less important in the first selection, were checked later. Some of the words were borrowed from languages other than French and had slightly peculiar orthographic forms. These other properties are common for rare words and unlikely to make significant differences for French undergraduates that would be relevant for the objective of our experiment. However, three words, one from each category, were canceled after this check. The total number of items was thus reduced to 42 (Table 1). Any thorough knowledge of other languages by some of our participants was assumed to be rare, random, and thus negligible.

A separate set of 42 irregular nonwords was also constructed. They were as dissimilar from regular words as possible and consisted of 42 sequences of letters made up entirely of consonants, and thus unpronounceable. Fortytwo high-frequency words, with a relative frequency of over 27 (per million), according to the Lexique norms (New et al., 2001), were also chosen.

Experiential frequency. Frequency counts reflect corpus size (Burgess \& Livesay, 1998). The Lexique corpus has more than 31 million words, but frequency variance is larger for low-frequency words, which could reduce the equivalence of frequencies among our stimuli, making a count based on a linguistic corpus insufficiently representative of word frequencies actually encountered by French undergraduates. Thus, we assessed experiential frequency using students belonging to the same population as the one to which the participants of our main experiments belonged.

A total of 84 words were rated: 14 words for each of the main categories (KM words, UM words, and U words), matched a priori for linguistic frequency and described above, along with the 42 high-frequency KM words discussed earlier.

The words were printed in random order, 18 to a page, with a 7-point rating scale $(7=$ very frequent, $1=$ not frequent at all) printed alongside each word. The pages were assembled into booklets, with the pages in a different random order. The instructions had to be precise, because one major goal of the study was to disentangle familiarity

Table 1

Materials From Experiment 1

\begin{tabular}{cll}
\hline $\begin{array}{c}\text { Known Meaning } \\
\text { Words }\end{array}$ & $\begin{array}{c}\text { Unknown Meaning } \\
\text { Words }\end{array}$ & Unknown Words \\
\hline allergie & abscission & cattleya \\
ampère & ascite & colcothar \\
batavia & bernacle & columbar \\
bikini & calabre & copahu \\
daltonien & cochylis & gomphose \\
décibel & cycnéen & hamada \\
gingembre & diffraction & imanat \\
lasagne & dolence & lichaven \\
marathon & ectopie & masalchi \\
paëlla & endémie & mastaba \\
salami & indiction & maucawis \\
scoliose & périanthe & pataras \\
véranda & polyptère & puchero \\
voltage & protusion & savacou \\
\hline
\end{tabular}


from frequency. The participants were first reminded that there are French words that are common, that is, frequent, and others that are less frequent, rare, or even very rare. The instructions continued: "We all intuitively have some idea of this frequency or rareness. This, and only this, is what you have to rate, taking into consideration no other characteristic of the items. These, as you will see, differ greatly." The degrees of the scale were then presented: 1 was defined as corresponding to "items that seem to you nonexistent, i.e., you never come across them," 2 to "very rare items," 4 to "moderately frequent items," 7 to "very frequent items," and similarly for the intermediate degrees, 3,5 , and 6 . The participants were told to try to make maximum use of all degrees of the scale, including 2 and 6.

The participants were 54 undergraduate psychology students from the University of Poitiers who were native French speakers. They took part in this experiment as part of their classroom work.

The ratings of experiential frequency, averaged for items and categories of items, are shown in Table 2. Because there were 14 items in each main category, the 42 high-frequency words were randomly assigned to one of the three subgroups.

Two ANOVAs (using the Statistica program) were performed on the responses, by participants and by items. The main effect of categories was reliable in both analyses $\left[F_{1}(5,265)=1,717.61, p<.00001 ; F_{2}(5,78)=709.07\right.$, $p<.00001]$. The differences between high-frequency subgroups and the other categories were significant. The differences between $U$ words and other categories were also significant: $\mathrm{U}$ words versus $\mathrm{UM}$ words $\left[F_{1}(1,53)=\right.$ $\left.38.16, p<.00001 ; F_{2}(1,78)=6.16, p<.015\right]$; U words versus KM words $\left[F_{1}(1,53)=67.74, p<.00001\right.$; $\left.F_{2}(1,78)=9.80, p<.002\right]$. However, the critical differences between UM and KM words were not significant $\left[F_{1}(1,53)=.115, p=.73 ; F_{2}(1,78)=.41, p=.51, \mathrm{n} . \mathrm{s}\right]$.

Degrees of semantic knowledge. The task used to distinguish UM words from KM words in the selection phase was somewhat general in nature. It was based on the participants' feeling of knowing a word's meaning. With the use of only three categories to rate the words and with the production of a broad characterization of their meaning, if any, this procedure could cause the participants to inappropriately assess knowledge of the word meanings. Width of the categories could lead participants to place words whose meaning they felt they knew only partially or vaguely among the UM words. Thus, we carried out an additional rating task to assess the degrees of knowledge that the undergraduates felt they possessed regarding the words' meaning. This task was preferred to an alternative approach involving the verification of this knowledge because familiarity with the meaning rather than actual knowledge of it was central to the main experiments that follow. Only offline knowledge of word meaning was obviously involved in this task, irrespective of the possible online modification of this meaning by its context in sentence comprehension.

The participants were reminded that "we all have some idea of the mastery we have of a word's meaning and its extent. This is what you have to rate." Degree 1 was defined as corresponding to "items that are not associated with any meaning for you"; 2 , to "items whose meaning you know very badly"; 3 , to "items whose meaning you know fairly badly"; and, in contrast, 6, to "items whose meaning you know well"; and 7, to "items whose meaning you know very well." The participants were asked to do all they could to use all degrees of the scale.

The same 84 words that were used earlier were rated. The procedure was similar to that of the previous rating task, but with the different 7-point scale written on the pages $(7=$ well-known meaning, $1=$ devoid of meaning $)$. Twenty-five undergraduate students of psychology from the University of Poitiers, all native French speakers, took part in this experiment as part of their classroom work. The results are presented in Table 2.

Two ANOVAs (using the Statistica program) were performed on the responses, by participants and by items. The effect was reliable in both analyses $\left[F_{1}(5,120)=5,634\right.$, $\left.p<.0001 ; F_{2}(5,78)=370.31, p<.0001\right]$. The differences between high-frequency subgroups were significant between Subset 3 and Subsets 1 and 2. The corresponding values between Subsets 1 and 2 and low-frequency KM words were significant $\left[F_{1}(1,24)=120.03, p<.0001\right.$; $\left.F_{2}(1,78)=14.52, p<.00027\right]$. UM words had a significantly higher rating than $\mathrm{U}$ words $\operatorname{did}\left[F_{1}(1,24)=307.94\right.$, $\left.p<.0001 ; F_{2}(1,78)=17.44, p<.00008\right]$. UM words were significantly and largely different from KM words

Table 2 Mean Rated Experiential Frequency, Knowledge of Meaning, and Familiarity for Each Category of Words

\begin{tabular}{|c|c|c|c|c|c|c|c|c|c|}
\hline \multirow[b]{2}{*}{ Word Category } & \multicolumn{3}{|c|}{ Experiential Frequency } & \multicolumn{3}{|c|}{ Knowledge of Meaning } & \multicolumn{3}{|c|}{ Familiarity } \\
\hline & $M$ & $S D\left(F_{1}\right)$ & $S D\left(F_{2}\right)$ & $M$ & $S D\left(F_{1}\right)$ & $S D\left(F_{2}\right)$ & $M$ & $S D\left(F_{1}\right)$ & $S D\left(F_{2}\right)$ \\
\hline Known meaning & 1.67 & .59 & .17 & 5.92 & .17 & .70 & 5.94 & .23 & .38 \\
\hline Unknown meaning & 1.65 & .66 & .23 & 1.88 & .15 & .77 & 1.93 & .29 & .62 \\
\hline Unknown & 1.34 & .44 & .08 & 1.10 & .12 & .14 & 1.12 & .11 & .08 \\
\hline Frequent (Subset 1) & 5.93 & .68 & .52 & 6.45 & .20 & .38 & 6.62 & .16 & .21 \\
\hline Frequent (Subset 2) & 5.90 & .67 & .35 & 6.47 & .19 & .37 & 6.59 & .13 & .16 \\
\hline Frequent (Subset 3) & 5.83 & .73 & .41 & 6.56 & .11 & .23 & 6.64 & .13 & .17 \\
\hline
\end{tabular}

Note- $S D\left(F_{1}\right)$, by participants; $S D\left(F_{2}\right)$, by items. 
$\left[F_{1}(1,24)=6,258.83, p<.00001 ; F_{2}(1,78)=470.75\right.$, $p<.00001]$. These results validated the assignments made in the selection phase.

\section{EXPERIMENT 1}

Word familiarity is generally considered to be highly correlated with frequency, particularly in the French language (Fraisse, Noizet, \& Flament, 1962). However, certain results have contradicted this correlation (Connine, Mullenix, Shernoff, \& Yelen, 1990). Thus, considering the fact that the meaning of a word, as well as its form, might contribute to its familiarity, the following question could be asked for these stimuli: Will our UM words actually be rated as having the same degree of familiarity as do KM words matched to them on a number of different dimensions, in particular, on linguistic and experiential frequency?

\section{Method}

Participants. Fifty undergraduate students of psychology from the University of Poitiers, all native French speakers, took part in this rating as part of their classroom work.

Materials and Procedure. Rated word familiarity was assessed for the 84 previous words, 14 for each of the three main experimental categories - KM, UM, and U words - plus the 42 high-frequency words. The participants were required "to estimate the familiarity of the words, i.e., to what extent you readily hear them, see them or use them." The procedure was similar to that used in the rating tasks described above, but it employed a different 7-point rating scale $(7=$ very familiar, $1=$ not familiar at all $)$.

\section{Results}

The ratings of familiarity, averaged for words and categories of words, are presented in Table 2.

Two ANOVAs (using the Statistica program) were performed on the responses, on participants, and on items. The effect was reliable in both analyses $\left[F_{1}(5,245)=\right.$ $\left.9,087.13, p<.00001 ; F_{2}(5,78)=860.26, p<.00001\right]$. The differences between high-frequency subgroups were not significant, but the difference between these and low-frequency KM words was $\left[F_{1}(1,49)=366.97\right.$, $\left.p<.00001 ; F_{2}(1,78)=48.17, p<.0001\right]$. The difference between $U$ words and UM words was significant $\left[F_{1}(1,49)=309.11, p<.0001 ; F_{2}(1,78)=42.25, p<\right.$ $.0001]$. A comparison of the scores for $U$ words with the fixed value of 1 was also found to be significant $[t=10.9$, $p<.01]$.

The difference in familiarity between UM words and KM words was very reliable in both analyses $\left[F_{1}(1,49)=\right.$ $\left.5,983.38, p<.00001 ; F_{2}(1,78)=1,039.23, p<.0001\right]$.

\section{Discussion}

First of all, these results show that rated familiarity is greater for frequent KM words than for infrequent ones. This is consistent with the high correlation between printed word frequency and rated familiarity found in other studies.

However, the main results for word familiarity rating were that (1) UM words had a lower degree of rated fa- miliarity than did KM words matched with them in many respects, including linguistic frequency and experiential frequency; (2) UM words had a higher degree of rated familiarity than completely U words; and (3) the difference in rated familiarity was less between UM words and $\mathrm{U}$ words (.81 on average on our scale) than between UM words and KM words (4.01 on the same scale). These results complement those showing that rated familiarity varies greatly among low-frequency words (Connine et al., 1990).

The results also indicate that the knowledge speakers have of the meaning of a word is highly correlated with the ratings of familiarity for this word. Thus, the idea that there is any single causal relationship between rated familiarity and word frequency must be reconsidered. Our results suggest that the rating of a KM word does not express a single global state of familiarity associated with this word, as is commonly believed, but rather a compound of at least two distinct familiarity values, each associated with one of the two main parts of the word representation, form and meaning.

The much lower rated familiarity value for UM than for KM words also indicates that familiarity with meaning contributes more to the total rated familiarity for KM words than does familiarity with the word form. This agrees with the assumption presented above that there is a greater increase in familiarity whenever speakers come into contact with a KM word than when they encounter a UM word because of the activation of both the word form representation and, for the former, its meaning. Familiarity with these two representations may be simultaneously, but unequally, increased when the word is processed, thus producing more long-term memory growth for meaning than for form representation. It can also be plausibly argued that semantic knowledge is more distinctive than orthographic knowledge: There is a much richer and more diverse set of representations for meaning than for word forms. Further support for this view comes from the fact that, if it is true, the separate meanings of ambiguous words should acquire different conditional probabilities and degrees of familiarity as a function of past contexts encountered by the speaker. This is consistent with most of the data on ambiguous words.

Another interesting result for word familiarity rating is that the words previously classified as unknown by students from the same population nevertheless had a rated familiarity significantly different from 1 , the lowest value on the scale - that is, from the theoretical zero. This nonzero familiarity cannot have been due to a specific knowledge of the representation of these stimuli as words, but could have been caused by some knowledge of their general form. These words are word-like; that is, they have a general linguistic regularity, both in speech and in writing. Thus, although they were judged to be nonwords, this basic lexicality could be recognized by the participants and result in their nonzero familiarity rating. If this is indeed the case, irregular nonwords, such as those formed from consonants, should have a rated familiarity of 1 (i.e., 
Table 3

\begin{tabular}{|c|c|c|c|c|c|c|}
\hline \multirow{2}{*}{$\begin{array}{l}\text { Experimental } \\
\text { Condition }\end{array}$} & \multicolumn{3}{|c|}{ Context A } & \multicolumn{3}{|c|}{ Context B } \\
\hline & $M$ & $S D\left(F_{1}\right)$ & $S D\left(F_{2}\right)$ & $M$ & $S D\left(F_{1}\right)$ & $S D\left(F_{2}\right)$ \\
\hline $\begin{array}{l}\text { Modified known } \\
\text { meaning words }\end{array}$ & 4.89 & .15 & .43 & 1.85 & .22 & .29 \\
\hline $\begin{array}{l}\text { Modified unknown } \\
\text { meaning words }\end{array}$ & 3.96 & .24 & .63 & 1.44 & .15 & .24 \\
\hline $\begin{array}{l}\text { Modified unknown } \\
\text { words }\end{array}$ & 3.34 & .13 & .75 & 1.24 & .13 & . 13 \\
\hline $\begin{array}{l}\text { Sequences of } \\
\text { consonants }\end{array}$ & 1.49 & .16 & .19 & 1.00 & & \\
\hline $\begin{array}{l}\text { Frequent } \\
\text { meaningful words }\end{array}$ & & & & 6.21 & & \\
\hline
\end{tabular}

zero) or near to 1. A particular rating task, performed in the context of Experiment 2 below, showed that they actually have zero or near-zero familiarity (rated familiarity of 1) (Table 3).

To summarize, the ratings support our assumption that there are two main combinable components of familiarity associated with word representations. One is a familiarity with the form of words, comprising basic lexicality, which was active for $\mathrm{U}$ words, and familiarity with the specific word form, which contributed to the higher ratings of UM words. The second is another type of familiarityfamiliarity with the word meaning-which contributed to the even higher ratings obtained for KM words.

\section{EXPERIMENTS 2A AND 2B}

The existence of the assumed components of familiarity was investigated in Experiment 1 by means of word familiarity ratings. These components might also be assumed to play a role in the processing and rating of pseudowords derived from these words. It was assumed that modifying the form of the stimuli by replacing a single letter in them would lower their global familiarity, but that the pseudowords would laterally activate the form of their original neighbor word and its meaning, if it had one (Forster \& Hector, 2002), thus conserving a contribution of the assumed components of familiarity to the processing and rating of pseudowords.

We postulated that full familiarity with the meaning of previous KM words would be lost when these were changed into pseudowords (KM-Pwords), but that these might still be able to laterally activate the meaning of the original neighbor KM words while being processed for a rating decision. Full familiarity with the KM word's specific form would also be lost, but KM-Pwords might still be able to activate familiarity with the specific word form of the original KM stimulus. Familiarity with a general word form would be preserved because the replacement of a single letter would not destroy the orthographic lexicality of the words. We similarly postulated that UMPwords would continue to generate no familiarity with any meaning and cease to arouse full familiarity with a specific word form, but still be capable of laterally activating familiarity with the specific word form of the corresponding original UM stimulus. Familiarity with the general word form would persist. Finally, U-Pwords would undergo no loss of familiarity with a meaning or a specific word form, whereas familiarity with a general word form would be conserved. We therefore predicted that familiarity ratings would be higher for KM-Pwords than for UM-Pwords and higher for UM-Pwords than for U-Pwords.

We also assumed that the differences, if there were any, among the mean familiarity values of the pseudowords would appear more readily if they were presented in opposition to true nonwords. This interface could be achieved by simply requesting the rating of strings of consonants together with true nonwords. The additional presence of frequent actual words would act as a high anchor and reduce differences. Two experiments were thus devised, both using the same procedure as in Experiment 1. Experiment $2 \mathrm{~A}$ involved only the pseudowords plus the strings of consonants, whereas Experiment 2B additionally made use of the 42 frequent words used in Experiment 1.

\section{Method}

Participants. Sixty participants (30 in Experiment 2A, 30 in Experiment 2B) took part in these rating tasks. They were undergraduate students of psychology from the University of Poitiers and were native French speakers. They were similar in all respects to the participants in Experiment 1.

Materials and Procedure. Three sets of stimuli were used. There were 42 pseudowords - 14 derived from KM words, 14 from UM words, and 14 from U words. The previous stimuli were modified by changing either an initial, middle, or final letter in the original words to eliminate the possibility of the pseudowords' being processed on the basis of the order of their letters (Chambers \& Forster, 1975). The diacritics from the base words were preserved. All the pseudowords were pronounceable. None had orthographic neighbors other than the original word. The 42 sequences of consonants and 42 high-frequency words described in the Selection section above were also used.

The procedure was the same as in the previous rating task - that is, line-by-line familiarity judgments on a 7-point rating scale. Only the pseudowords plus the strings of consonants were used in Experiment $2 \mathrm{~A}$ (Context $\mathrm{A}$ ). The same stimuli plus the frequent words were used in Experiment 2B (Context B). 


\section{Results}

Table 3 shows the data collected in Experiments 2A and $2 \mathrm{~B}$ in the two contexts. Several ANOVAs were performed on these data. In Context $\mathrm{A}, F_{1}(2,58)=529.12$, $p<.00001$ and $F_{2}(2,39)=21.79, p<.00001$. The contrasts were significant: KM-Pwords versus UM-Pwords $\left[F_{1}(1,29)=312.46, p<.00001 ; F_{2}(1,39)=15.69\right.$, $p<.0003]$; UM-Pwords versus U-Pwords $\left[F_{1}(1,29)=\right.$ $\left.159.38, p<.00001 ; F_{2}(1,39)=6.72, p<.013\right]$. A comparison of the scores for U-Pwords to those for sequences of consonants was also found to be significant $[t=4.70$, $p<.01]$.

In Context $\mathrm{B}$, the main effect was significant $\left[F_{1}(2,58)=\right.$ $\left.110.64, p<.0001 ; F_{2}(2,39)=24.88, p<.00001\right]$. The contrast between KM-Pwords and UM-Pwords was also significant $\left[F_{1}(1,29)=74.88, p<.0001 ; F_{2}(1,39)=21.76\right.$, $p<.0003]$. Scores for UM-Pwords versus U-Pwords were significant $\left[F_{1}(1,29)=37.97, p<.00001 ; F_{2}(1,39)=\right.$ $5.67, p<.03]$. A comparison of the scores for U-Pwords and those for sequences of consonants was also significant $(t=4.86, p<.001)$.

\section{Discussion}

The first result of Experiments 2A and 2B was that the values of rated familiarity for the three categories of pseudowords were similarly ordered in both conditions as they were in Experiment 1. This order depends on the nature of the pseudowords - that is, the nature of the underlying original stimuli.

This result is again in agreement with the idea that knowledge of a word form and of a word's meaning largely intervenes in judgments of familiarity. The role of knowledge in this situation differs from that involved in Experiment 1: It is due not to the form or meaning of the pseudowords themselves, but to those of their unique neighbor. This is presumably attributable to a greater derived familiarity, or familiarity-by-analogy, which could be formulated as an implicit feeling that "this stimulus resembles a word I know" or "resembles a word I know and whose meaning I know." The rating differences again indicate the respective contributions to pseudoword ratings of the initially postulated components of familiarity. They also show that these components are not attached to the representations of the specific form or meaning themselves because pseudowords have none, but that their contribution depends instead on the processing involved in the task.

A second result came from a comparison of Experiments $2 \mathrm{~A}$ and $2 \mathrm{~B}$ : Rating values depend on the stimulus context. This again indicates that ratings do not simply reflect a single invariable property stored in long-term memory along with the original words, but are the result of the processing involved in the task of relating the two.

This view has been given separate support by the results obtained by Le Ny and Cordier (2004). These authors presented these pseudowords online in a lexical decision task that also made use of normal words. "No" responses, which were the relevant variable, were longer for KM-Pwords than for UM-Pwords and longer still for U-Pwords. The order for processing times was, then, KMPwords > UM-Pwords > U-Pwords. This order complied with the order found in familiarity rating for these pseudowords and the order KM-words, UM-words, U-words found in the familiarity ratings for the corresponding original stimuli.

\section{GENERAL DISCUSSION}

The ratings of words and pseudowords described in this article revealed differences in semantic understanding of $\mathrm{KM}$ words, UM words, and $\mathrm{U}$ words of similar linguistic and experiential frequency, as well as of pseudowords derived from them. By assuming that two components are involved in word familiarity judgments, it was possible to account for these results. However, it is unlikely that these components are themselves some kind of subrepresentation stored in memory alongside the word representations. It is more likely that they intervene as knowledge, or ana$\log$ knowledge, in the processing that leads to the rating decisions. They could be involved in this rating, much as they are in the processing that leads to lexical decision, as a transient state and feeling of familiarity.

First, this view is compatible with several models concerning the role of word meaning in lexical decision. Hino and Lupker (1996) and Hino et al. (2002) assumed that lexical decisions were based primarily on the level of orthographic familiarity with the stimuli and that semantic processing is a source of feedback activation to the orthographic level. It is likely that phonology also is activated during processing. The dual route cascaded model of Coltheart, Rastle, Perry, Langdon, and Ziegler (2001) presented an interactive view of the orthography-phonology correspondence, but word frequency rather than familiarity was considered in the corresponding experiments. Our use of the notion of familiarity can primarily be related to that of "harmony" in Joordens and Becker's (1997) attractor network model of word recognition. This model belongs to the general family of memory models that attribute an important role to familiarity in recognition (Balota \& Chumbley, 1984; Gillund \& Shiffrin, 1984; Goldinger, 1998; Hintzman, 1984; Murdock, 1982; Ratcliff \& McKoon, 1988), and harmony is the theoretical equivalent of a transient state of familiarity during processing. Joordens and Becker have said that "harmony (or familiarity) gradually increases as information is accrued" during the lexical decision task. "If participants are basing their responses on a familiarity value, that value (and the influences affecting it) should change as a stimulus is processed" (Joordens \& Becker, 1997, p. 1098).

If we consider familiarity rating as the output from stimulus processing, we can understand that the final global familiarity decision depends on a feeling of familiarity generated on the basis of several different memory sources during stimulus processing. Much as they would for a lexical decision, distinct components of this feeling of familiarity would come from these memory sources 
and would add up to create a global transient state of familiarity, the level of which would determine the final rating decision.

The significance of the various components of word familiarity in word processing is presumably different in different situations, depending on the task, the nature of the stimuli, the context created for a given stimulus by all other stimuli, as shown above, as well as other conditions. Not all experiments need to discriminate the sources of familiarity. However, no matter what interpretation is provided for the findings reported in this study, they underline the importance of considering the existence of multisource components of word familiarity when this notion is used in experiments.

\section{REFERENCES}

Amano, S., Kondo, T., \& KaKehi, K. (1995). Modality dependency of familiarity ratings of Japanese words. Perception \& Psychophysics, 57, 598-603.

ANDREws, S. (1997). The effect of orthographic similarity on lexical retrieval: Resolving neighborhood conflicts. Psychonomic Bulletin \& Review, 4, 439-461.

Azuma, T., \& Van Orden, G. C. (1997). Why SAFE is better than FAST: The relatedness of a word's meanings affects lexical decision times. Journal of Memory \& Language, 36, 484-504.

Balota, D. A., \& Chumbley, J. I. (1984). Are lexical decisions a good measure of lexical access? The role of word frequency in the neglected decision stage. Journal of Experimental Psychology: Human Perception \& Performance, 10, 340-357.

Balota, D. A., Pilotti, M., \& Cortese, M. J. (2001). Subjective frequency estimates for 2,938 monosyllabic words. Memory \& Cognition, 29, 639-647.

Balota, D. A., \& Spieler, D. H. (1999). Word frequency, repetition, and lexicality effects in word recognition tasks: Beyond measures of central tendency. Journal of Experimental Psychology: General, 128, 32-55.

Borowsky, R., \& Masson, M. E. J. (1996). Semantic ambiguity effects in word identification. Journal of Experimental Psychology: Learning, Memory \& Cognition, 22, 63-85.

Burgess, C., \& Livesay, K. (1998). The effect of corpus size in predicting reaction time in a basic word recognition task: Moving on from Kučera and Francis. Behavior Research Methods, Instruments, \& Computers, 30, 272-277.

Chambers, S. M., \& Forster, K. I. (1975). Evidence for lexical access in a simultaneous matching task. Memory \& Cognition, 3, 549-559.

Cole, P., Beauvillain, C., Pavard, B., \& Segui, J. (1986). Organisation morphologique et accès au lexique. L'Année Psychologique, 86, 349-365.

Coltheart, M., Rastle, K., Perry, C., Langdon, R., \& Ziegler, J. (2001). DRC: A dual route cascaded model of visual word recognition and reading aloud. Psychological Review, 108, 204-256.

Connine, C., Mullennix, J., Shernoff, E., \& Yelen, J. (1990). Word familiarity and frequency in visual and auditory word recognition. Journal of Experimental Psychology: Learning, Memory, \& Cognition, 16, 1084-1096.

Content, A., Mousty, P., \& Radeau, M. (1990). BRUleX: Une base de données lexicales informatisée pour le français écrit et parlé. L'Année Psychologique, 90, 551-566.

Content, A., \& Radeau, M. (1988). Données statistiques sur la structure orthographique du français. Cahiers de Psychologie Cognitive, 8, 399-404.

Durkin, K., \& Manning, G. (1989). Polysemy and the subjective lexicon: Semantic relatedness and the salience of intraword senses. Journal of Psycholinguistic Research, 18, 577-612.

ForsteR, K. I. (1985). Lexical acquisition and the modular lexicon. Language \& Cognitive Processes, 1, 87-108.
Forster, K. I., \& Hector, J. (2002). Cascaded versus noncascaded models of lexical and semantic processing: The turple effect. Memory \& Cognition, 30, 1106-1116.

Fraisse, P., Noizet, G., \& Flament, C. (1962). Fréquence et familiarité du vocabulaire. In J. de Ajuriaguerra, F. Bresson, P. Fraisse, B. Inhelder, P. Oléron, \& J. Piaget (Eds.), Problèmes de psycholinguistique (pp. 157-167). Paris: Presses Universitaires de France.

Gernsbacher, M. A. (1984). Resolving 20 years of inconsistent interactions between lexical familiarity and orthography, concreteness and polysemy. Journal of Experimental Psychology: General, 113, 256-281.

Gillund, G., \& Shiffrin, R. M. (1984). A retrieval model for both recognition and recall. Psychological Review, 91, 1-67.

GoldingER, S. D. (1998). Echoes of echoes? An episodic theory of lexical access. Psychological Review, 105, 251-279.

GRAINGER, J. (1990). Word frequency and neighborhood frequency effects in lexical decision and naming. Journal of Memory \& Language, 29, 228-244.

Grainger, J., O'Regan, J. K., Jacobs, A. M., \& Segui, J. (1989). On the role of competing word units in visual word recognition: The neighborhood frequency effect. Perception \& Psychophysics, 45, 189-195.

Grainger, J., O'Regan, J. K., Jacobs, A. M., \& Segui, J. (1992). Neighborhood frequency effects and letter visibility in visual word recognition. Perception \& Psychophysics, 51, 49-56.

Grainger, J., \& Segui, J. (1990). Neighborhood frequency effects in visual word recognition: A comparison of lexical decision and masked identification latencies. Perception \& Psychophysics, 47, 191-198.

HiNO, Y., \& LuPKER, S. J. (1996). Effects of polysemy in lexical decision and naming: An alternative to lexical access accounts. Journal of Experimental Psychology: Human Perception \& Performance, 22, 1331-1356.

Hino, Y., Lupker, S. J., \& Pexman, P. M. (2002). Ambiguity and synonymy effects in lexical decision, naming, and semantic categorization tasks: Interactions between orthography, phonology, and semantics. Journal of Experimental Psychology: Learning, Memory, \& Cognition, 28, 686-713.

HinTZMAN, D. L. (1984). MINERVA 2: A simulation model of human memory. Behavior Research Methods, Instruments, \& Computers, 16, 96-101.

Joordens, S., \& BeCKer, S. (1997). The long and short of semantic priming effects in lexical decision. Journal of Experimental Psychology: Learning, Memory \& Cognition, 23, 1083-1105.

Kawamoto, A. H., Farrar, W. T., \& Kello, C. T. (1994). When two meanings are better than one: Modeling the ambiguity advantage using a recurrent distributed network. Journal of Experimental Psychology: Human Perception \& Performance, 14, 601-609.

LE Ny, J.-F. (1989). Accès au lexique et compréhension du langage: La ligne de démarcation sémantique. Lexique, 8, 65-85.

LE NY, J.-F., \& CoRDIER, F. (2004). Contribution of word meaning and components of familiarity to lexical decision: A study with pseudowords constructed from words with known or unknown meaning. Current Psychology Letters: Behaviour, Brain, \& Cognition, 12(1), http://www.revues.org.

LimA, S. D., \& INHOFF, A. W. (1985). Lexical access during eye fixations in reading: Effects of word-initial letter sequence. Journal of Experimental Psychology: Human Perception \& Performance, 11, 272-285.

Masson, M. E. J., \& Borowsky, R. (1995). Unsettling questions about semantic ambiguity in connectionist models: Comment on Joordens and Besner (1994). Journal of Experimental Psychology: Learning, Memory, \& Cognition, 21, 509-514.

Morton, J. (1969). Interaction of information in word recognition. Psychological Review, 76, 165-178.

Morton, J. (1970). A functional model for memory. In D. A. Norman (Ed.), Models of human memory (pp. 203-254). New York: Academic Press.

MuRDock, B. B. (1982). A theory for the storage and retrieval of item and associative information. Psychological Review, 89, 609-626.

Murrell, G., \& Morton, J. (1974). Word recognition and morphemic structure. Journal of Experimental Psychology, 102, 963-968. 
New, B., Pallier, C., Ferrand, L., \& Matos, R. (2001). Une base de données lexicales du français contemporain: Lexique. L'Année Psychologique, 101, 447-462.

Pecher, D. (2001). Perception is a two-way junction: Feedback semantics in word recognition. Psychonomic Bulletin \& Review, 8, 545-551.

RADEAU, M. (1991). Le traitement séquentiel des mots. In R. Kolinsky, J. Morais, \& J. Segui (Eds.), La reconnaissance des mots dans les différentes modalités sensorielles: Études de psycholinguistique cognitive (pp. 81-95). Paris: Presses Universitaires de France.

RatclifF, R., \& McKoon, G. (1988). A retrieval theory of priming in memory. Psychological Review, 95, 385-408.

Schuberth, R. E., \& Eimas, P. D. (1977). Effects of context on the classification of words and nonwords. Journal of Experimental Psychology: Human Perception \& Performance, 3, 27-36.

Segui, J., \& Grainger, J. (1990). Priming word recognition with orthographic neighbors: The effects of relative prime-target frequency. Journal of Experimental Psychology: Human Perception \& Performance, 16, 65-76.

Stone, G. O., \& VAN ORden, G. C. (1993). Strategic control of processing in word recognition. Journal of Experimental Psychology: Human Perception \& Performance, 19, 744-774.

Van Orden, G. C., Bosman, A. M. T., Goldinger, S. D., \& Farrar, W. T. (1997). A recurrent network account of reading, spelling and dyslexia. In J. W. Donahoe \& V. P. Dorsel (Eds.), Neural network models of cognition: Biobehavioral foundations (pp. 522-538.). Amsterdam: Elsevier.

VAN ORDEN, G. C., \& Goldinger, S. D. (1994). Independence of form and function in cognitive systems explains perception of printed words. Journal of Experimental Psychology: Human Perception \& Performance, 20, 1269-1291.
Whittlesea, B. W. A., \& Cantwell, A. L. (1987). Enduring influence of the purpose of experiences: Encoding-retrieval interactions in word and pseudoword perception. Memory \& Cognition, 15, 465-472.

\section{ARCHIVED MATERIALS}

The following materials associated with this article may be accessed through the Psychonomic Society's Norms, Stimuli, and Data archive, http://www.psychonomic.org/archive.

To access these files, search the archive for this article using the journal (Behavior Research Methods), the first author's name (Cordier), and the publication year (2005).

FILE: Cordier-BRM-2005.zip

DESCRIPTION: The compressed archive file contains two files:

Cordier2005norms.xls, containing the norms developed by Cordier and Le Ny (2005) as a 36K tab-delimited text file generated by Excel 1997. Each row represents one of 84 French words and 84 pseudowords; each column, Mean, $S D$, or Range of the three dependent measures (experiential frequency, degree of knowledge, and rated familiarity).

Cordier2005aboutnorms.txt, a description of the content of Cordier2005norms.xls, including extended definitions of the selected words and pseudowords of the document (a 1K plain text file).

AUTHOR'S E-MAIL ADDRESS: francoise.cordier@mshs.univ-poitiers.fr.

\section{NOTE}

1. In French: "pourrait être un mot." French has only one verb to express the modality expressed by can or may in English, but the conditional form pourrait clearly refers to a possible word. 
APPENDIX

Materials From Experiment 1: Details of Ratings on a 7-Point Scale for Experiential Frequency, Degree of Meaning Knowledge, and Familiarity

\begin{tabular}{|c|c|c|c|}
\hline Words & $\begin{array}{c}\text { Experiential } \\
\text { Frequency }\end{array}$ & $\begin{array}{c}\text { Degree of } \\
\text { Meaning } \\
\text { Knowledge }\end{array}$ & Familiarity \\
\hline \multicolumn{4}{|c|}{ Known Meaning } \\
\hline allergie & 1.61 & 6.64 & 6.50 \\
\hline ampère & 1.94 & 5.00 & 5.74 \\
\hline batavia & 1.48 & 5.16 & 5.78 \\
\hline bikini & 1.57 & 6.39 & 6.10 \\
\hline daltonien & 1.65 & 5.80 & 5.64 \\
\hline décibel & 1.88 & 5.80 & 5.96 \\
\hline gingembre & 1.92 & 6.08 & 5.36 \\
\hline lasagne & 1.76 & 6.48 & 6.24 \\
\hline marathon & 1.91 & 5.84 & 5.94 \\
\hline paëlla & 1.83 & 6.68 & 6.42 \\
\hline salami & 1.57 & 6.08 & 5.92 \\
\hline scoliose & 1.94 & 5.16 & 5.72 \\
\hline véranda & 1.79 & 6.76 & 6.40 \\
\hline voltage & 1.46 & 4.64 & 5.38 \\
\hline \multicolumn{4}{|c|}{ Unknown Meaning } \\
\hline abscission & 1.61 & 2.16 & 1.84 \\
\hline ascite & 1.48 & 1.48 & 1.42 \\
\hline bernacle & 1.50 & 1.24 & 1.46 \\
\hline calabre & 1.70 & 2.00 & 2.06 \\
\hline cochylis & 1.38 & 1.68 & 1.68 \\
\hline cycnéen & 1.59 & 1.00 & 1.28 \\
\hline diffraction & 2.11 & 3.72 & 2.54 \\
\hline dolence & 1.44 & 1.88 & 3.06 \\
\hline ectopie & 1.46 & 1.44 & 1.56 \\
\hline endémie & 1.77 & 2.44 & 2.04 \\
\hline indiction & 1.87 & 1.76 & 2.06 \\
\hline périanthe & 1.76 & 1.16 & 1.24 \\
\hline polyptère & 2.06 & 1.20 & 1.58 \\
\hline protusion & 1.44 & 2.84 & 3.00 \\
\hline \multicolumn{4}{|l|}{ Unknown } \\
\hline cattleya & 1.27 & 1.28 & 1.10 \\
\hline colcothar & 1.31 & 1.04 & 1.14 \\
\hline columbar & 1.27 & 1.04 & 1.40 \\
\hline copahu & 1.25 & 1.04 & 1.06 \\
\hline gomphose & 1.40 & 1.00 & 1.02 \\
\hline hamada & 1.44 & 1.04 & 1.20 \\
\hline imanat & 1.42 & 1.04 & 1.08 \\
\hline lichaven & 1.25 & 1.08 & 1.16 \\
\hline masalchi & 1.40 & 1.12 & 1.06 \\
\hline mastaba & 1.46 & 1.56 & 1.08 \\
\hline maucawis & 1.31 & 1.00 & 1.08 \\
\hline pataras & 1.37 & 1.08 & 1.14 \\
\hline puchero & 1.26 & 1.08 & 1.18 \\
\hline savacou & 1.39 & 1.04 & 1.04 \\
\hline
\end{tabular}

(Manuscript received January 19, 2004;

revision accepted for publication September 11, 2004.) 